\title{
Optic disc morphology in pigmentary glaucoma
}

\author{
Jost B Jonas, Albert Dichtl, Wido M Budde, Peter Lang
}

\begin{abstract}
Aim-To evaluate the morphology of the optic nerve head in eyes with pigmentary glaucoma.

Methods-Colour stereo optic disc photographs of 62 patients with pigmentary glaucoma and 566 patients with primary open angle glaucoma were morphometrically evaluated. By prestudy selection, mean visual field defect and neuroretinal rim area were not significantly different between the two groups $(p=0.89$ and $\mathrm{p}=0.45)$.
\end{abstract}

Results-The pigmentary glaucoma group did not vary significantly $(p>0.10)$ from the primary open angle glaucoma group in size and shape of the optic disc, configuration of neuroretinal rim, depth of optic cup, area of alpha zone of parapapillary atrophy, diameter of retinal vessels at the disc border, and frequency of disc haemorrhages and localised retinal nerve fibre layer defects. The beta zone of parapapillary atrophy was slightly, but not statistically significantly $(p=0.06)$, smaller in the pigmentary glaucoma group. The mean maximal intraocular pressure and mean intraocular pressure amplitude were significantly $(p<0.001)$ higher in the pigmentary glaucoma group.

Conclusions-In contrast with the characteristic morphology of the anterior segment and despite significantly higher intraocular pressure peaks and a larger pressure amplitude, eyes with pigmentary glaucoma compared with eyes with primary open angle glaucoma do not show a pathognomonic morphology of the optic disc and retinal nerve fibre layer. The slightly smaller beta zone of parapapillary atrophy may correspond to higher intraocular pressure in pigmentary glaucoma. (Br F Ophthalmol 1998;82:875-879)

Department of Ophthalmology and Eye Hospital, University

Erlangen-Nürnberg, Germany

J B Jonas

A Dichtl

W M Budde

P Lang

Correspondence to: Dr J Jonas,

Universitäts-Augenklinik, Schwabachanlage 6, 91054 Erlangen, Germany.
Pigmentary glaucoma is a special form of secondary open angle glaucoma in which melanin granules from the iris pigment epithelium are distributed through the eye. ${ }^{12}$ The condition is characterised by moderate myopia with a deep anterior chamber, radial defects in the peripheral iris pigment epithelium, retrocorneal pigmentation as Krukenberg's spindle, hyperpigmentation of the trabecular meshwork, Eggert's line of pigmentation of the hyaloideocapsular ligament, and equatorial retinal degenerations. The condition more commonly affects males and usually presents in the second to fifth decade of life. ${ }^{3}$

In view of the specific features of the anterior segment found in eyes with pigmentary glau- coma, the present study was conducted to determine whether the optic nerve head also showed peculiarities typical of the condition.

\section{Patients and methods}

The study included 62 patients with pigmentary glaucoma who were compared with 566 patients suffering from primary open angle glaucoma (Table 1). By selection, the two study groups did not vary significantly in visual field defect (mean 6.03 (SD 5.89) dB versus 6.15 (5.94), $\mathrm{p}=0.89$; Mann-Whitney test) and neuroretinal rim area $\left(1.18(0.47) \mathrm{mm}^{2}\right.$ versus $\left.1.16(0.37) \mathrm{mm}^{2}(\mathrm{p}=0.45)\right)$. All participants of the study were white. They were part of a prospective study on the biomorphometry of the optic nerve involving all patients coming to the hospital with an anomaly or disease of the optic nerve. The patients in the present study - that is, those with pigmentary glaucoma, had not been examined separately in a previous investigation. The patients with primary open angle glaucoma, whose optic disc data were used to compare with those of the patients with pigmentary glaucoma, had been included in other recent studies where different questions were addressed. ${ }^{4}$

Criteria for the diagnosis of glaucoma were an open anterior chamber angle, measurements or history of an elevated intraocular pressure above $21 \mathrm{~mm} \mathrm{Hg}$, and a glaucomatous visual field defect. A glaucomatous visual field defect was defined as a Octopus G1 field with (a) at least three adjacent test points having a deviation of equal to or greater than $5 \mathrm{~dB}$ and with one test point with a deviation more than $10 \mathrm{~dB}$ lower, (b) at least two adjacent test points with a deviation equal to or greater than $10 \mathrm{~dB}$, (c) at least three adjacent test points with a deviation equal to or greater than $5 \mathrm{~dB}$ abutting the nasal horizontal meridian, and (d) a mean visual field defect of more than $2 \mathrm{~dB}$.

In the eyes affected by primary open angle glaucoma, no obvious reason for the elevation of intraocular pressure could be detected. The eyes with pigmentary glaucoma were characterised by radial translucent defects in the periphery of the iris pigment epithelium, and a hyperpigmentation in the posterior and anterior chamber including a pigmentation of the hyaloideocapsular ligament, Krukenberg's spindle, melanin granules on the iris surface, a pronounced hyperpigmentation of the anterior chamber angle, and pigment dispersion upon mydriasis. Other reasons for pigment dispersion such as intraocular surgery or herpetic iritis had been excluded.

Intraocular pressure had been measured for all patients by Goldmann applanation tonometry in day and night pressure profiles containing at least four measurements between 
Table 1 Composition of the study groups (mean (SD))

\begin{tabular}{|c|c|c|c|c|c|}
\hline & $\begin{array}{l}\text { Pigmentary } \\
\text { glaucoma }\end{array}$ & $\begin{array}{l}\text { Primary open } \\
\text { angle glaucoma }\end{array}$ & p Value & $\begin{array}{l}\text { Primary open } \\
\text { angle } \\
\text { glaucoma } \\
\text { adjusted for } \\
\text { refractive error } \\
\text { and age }\end{array}$ & p Value \\
\hline $\mathrm{n}$ & 62 & 566 & & 102 & \\
\hline Women/men & $13 / 49$ & $276 / 290$ & $<0.001$ & $66 / 36$ & $>0.05(\mathrm{~ns})$ \\
\hline Age (years) & $44.2(9.4)$ & $59.2(13.9)$ & $<0.0001$ & $44.7(7.8)$ & $0.42(\mathrm{~ns})$ \\
\hline Range & $26-64$ & $22-89$ & & $23-53$ & \\
\hline Refractive error (D) & $-3.54(2.64)$ & $-0.91(2.62)$ & $<0.0001$ & $-2.82(2.05)$ & 0.17 (ns) \\
\hline Range & -9.50 to +0.50 & -9.25 to +6.75 & & -7.5 to -0.25 & \\
\hline
\end{tabular}

p Value $=$ significance of differences between the pigmentary glaucoma group and the primary open angle glaucoma group adjusted or not adjusted for age and refractive error; ns = statistically not significant. optic disc was covered, then the projector refocused and the retinal nerve fibre layer evaluated. A localised defect of the retinal nerve fibre layer was defined as a wedge-shaped and not spindle-like defect, running towards or touching the optic disc border for not more than 60 degrees of the optic disc circumference. ${ }^{7}$

The photographs of the optic disc and retinal nerve fibre layer were evaluated independently of each other in a masked fashion without knowledge of the clinical diagnosis and the visual field data. Only one randomly selected eye per patient was taken for statistical analysis.

$4 \mathrm{pm}$ and 8 am (at about $5 \mathrm{pm}, 9 \mathrm{pm}$, midnight, and $7 \mathrm{am}$ ). The means of the four highest values and the four lowest values were recorded.

For all eyes, $15^{\circ}$ colour stereo optic disc transparencies had been taken using a Zeiss telecentric fundus camera. Mixed together with photographs of more than 500 patients with other forms of glaucoma or optic nerve diseases, the disc transparencies were projected in a scale of 1 to 15 . The outlines of the optic cup, optic disc, peripapillary scleral ring, and alpha zone and beta zone of parapapillary atrophy were plotted on paper and analysed morphometrically. The border of the optic disc was identical with the inner side of the peripapillary scleral ring. The optic cup was defined on the basis of contour and not of pallor. Correspondingly, in some eyes the area with cupping was larger than the area with pallor. Based on the stereoscopic impression obtained from viewing the stereo diapositives, the depth of the optic cup was estimated in a scale ranging from " 0 " for no cupping to " 5 " for very deep cupping. The reproducibility of the optic cup depth assessment examined in a previous study ${ }^{5}$ ranged between $2.0 \%$ and $8.9 \%$. Parapapillary atrophy was differentiated into two zones. The alpha zone was located in the periphery of the parapapillary region and was characterised by irregular hypopigmentation and hypopigmentation with a round border to the retina on its outer side. The beta zone was located between the alpha zone and the peripapillary scleral ring. It was whitish and showed visible sclera and visible large choroidal vessels. ${ }^{4}$ To obtain the measurements in millimetres or square millimetres, the ocular and photographic magnifications were corrected according to the Littmann method using the anterior corneal curvature and the refractive error. ${ }^{6}$

For 30 patients with pigmentary glaucoma (seven women, 23 men; age 43.6 (10.3) years; refractive error -3.66 (2.63) dioptres) and 146 patients with primary open angle glaucoma (77 women/69 men; age 59.7 (11.6) years; refractive error -0.91 (2.49) dioptres), wide angle photographs of the retinal nerve fibre layer were available. They had been taken and evaluated as reported recently. ${ }^{7}$ Instead of paper prints diapositives were developed. The slides were projected with a magnification of 15 times after maximal defocusing of the projector. The area of the blurred image of the

\section{Results} tive error was significantly more myopic $(p<0.0001)$, and there were significantly $(\mathrm{p}<0.001)$ more men than women in the group with pigmentary glaucoma compared with the group with primary open angle glaucoma (Table 1). Although size and shape of the optic disc and neuroretinal rim are statistically independent of age beyond the age of 15 years, ${ }^{8}$ we formed a subgroup of patients with primary open angle glaucoma which was adjusted for age and refractive error with the pigmentary glaucoma group. The percentage of patients in separate age groups each spanning over 15 years of life in the primary open angle glaucoma group was similar (plus or minus $8 \%$ ) to the percentage of patients in the same age groups in the pigmentary glaucoma group. Correspondingly, difference in age between the two groups was not significant $(p=0.42$; Mann-Whitney U-Wilcoxon test). The adjusted subgroup consisted of 102 patients with primary open angle glaucoma (Table 1 ). With the size and shape of the optic disc, neuroretipendent of $\operatorname{sex},{ }^{48}$ the differences in this variable were not taken into account.

The pigmentary glaucoma group did not vary significantly ( $\mathrm{p}>0.10$; Wilcoxon-MannWhitney test) from the primary open angle glaucoma groups in optic disc area, horizontal and vertical disc diameter, minimal and maximal disc diameter, ratio of minimal to maximal disc diameter, and disc form factor (Table 2). Correspondingly, the pigmentary glaucoma group did not differ significantly $(\mathrm{p}>0.10)$ from the primary open angle glaucoma group, adjusted and not adjusted for age and refractive error, in area and width of neuroretinal rim, horizontal and vertical cup/disc diameter ratios, quotient of horizontal to vertical cup/ disc diameter ratios, total and sectorial area of alpha zone and beta zone of parapapillary atrophy, diameters of retinal arterioles and venules at the optic disc border, frequency of optic disc haemorrhages, prevalence of localised retinal nerve fibre layer defects, and loss variance value of the perimetric examination (Table 2).

If the pigmentary glaucoma group was compared with a primary open angle glaucoma control group which was adjusted only for refractive error $(n=226$; age 58.0 (15.0) years; refractive error -3.39 (2.12) dioptres; optic
Age was significantly $(p<0.0001)$ lower, refracnal rim, and parapapillary atrophy being inde- 
Table 2 Measurements of the optic disc and intraocular pressure (mean (SD))

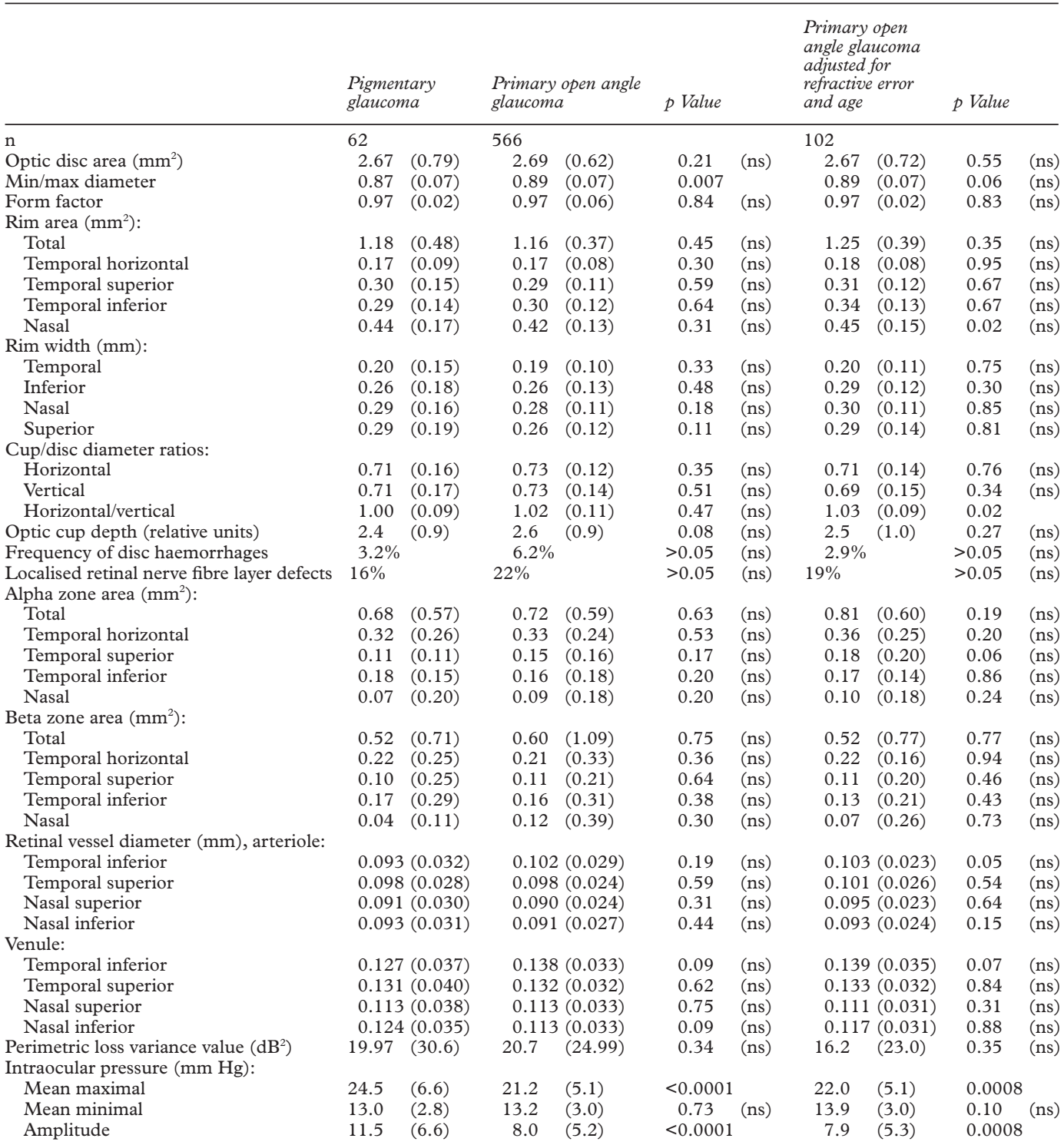

$\mathrm{p}$ Value $=$ significance of differences between the pigmentary glaucoma group and the primary open angle glaucoma group adjusted or not adjusted for age and refractive error; ns = statistically not significant.

disc area $2.67(0.67) \mathrm{mm}^{2}$; neuroretinal rim area: $\left.1.16(0.38) \mathrm{mm}^{2}\right)$, the difference in beta zone between the two groups was more pronounced and almost reached the level of $5 \%$ error of probability $\left(0.52(0.71) \mathrm{mm}^{2}\right.$ in pigmentary glaucoma versus 0.89 (1.42) $\mathrm{mm}^{2}$ in the control group; $\mathrm{p}=0.06$ ).

The mean maximal intraocular pressure measurements and the difference between the maximal and minimal intraocular pressure readings were significantly $(p<0.001)$ higher in the eyes with pigmentary glaucoma than in the eyes with primary open angle glaucoma. The mean minimal intraocular pressure values did not vary significantly $(\mathrm{p}=0.73)$ (Table 2$)$.

\section{Discussion}

The open angle glaucomas form a heterogeneous group of diseases, features of which vary in the level of intraocular pressure, age of the patients, prevalence of arterial hypotension, refractive error, and atrophic appearance of the posterior fundus. ${ }^{67-26}$ The appearance of the optic disc differs in the various forms of open angle glaucoma.
To give examples, eyes with the highly myopic type of primary open angle glaucoma have large and abnormally shaped optic discs with shallow and concentric cupping. Disc haemorrhages and localised retinal nerve fibre layer defects are relatively rare, parapapillary atrophy is pronounced, and intraocular pressure measurements are often in the normal range. ${ }^{1920222526}$ In eyes with the focal type of normal pressure glaucoma, size and shape of the optic disc is normal, optic disc cupping is deep and steep, frequencies of neuroretinal rim notches, disc haemorrhages, and localised retinal nerve fibre layer defects are relatively high, parapapillary atrophy is only slightly enlarged, and intraocular pressure is in the normal range. ${ }^{912} 2122$ Eyes with the age related atrophic type of primary open angle glaucoma usually show a pronounced parapapillary atrophy in combination with a marked fundus tessellation and a shallow and concentric disc cupping. Disc haemorrhages, rim notches, and localised retinal nerve fibre layer defects are relatively rare in this type of glaucoma. Intraocular pressure readings are often in the 
upper normal range or are only slightly elevated. ${ }^{11161719202223}$ In the juvenile onset type of primary open angle glaucoma and in secondary open angle glaucoma with high intraocular pressure, optic disc cupping is steep and deep. Frequencies of disc haemorrhages, neuroretinal rim notches, and localised retinal nerve fibre layer defects are low, parapapillary atrophy is small, and minimal and maximal values of intraocular pressure measurements are high. ${ }^{6121622}$ In eyes with secondary open angle glaucoma due to pseudoexfoliation of the lens, the optic disc size is normal or slightly smaller than in eyes with primary open angle glaucoma. The shape of the optic disc and neuroretinal rim, prevalence and size of parapapillary atrophy, and optic cup depth do not differ significantly between eyes with pseudoexfoliative glaucoma and eyes with primary open angle glaucoma. ${ }^{18} 24$

According to the results of the present study, eyes with secondary open angle glaucoma due to primary melanin dispersion syndrome (pigmentary glaucoma) do not show peculiarities of the optic disc and retinal nerve fibre layer which may be characteristic of this type of chronic open angle glaucoma. It is in contrast with the morphological abnormalities in the anterior segment of the eye which are pathognomonic for pigmentary glaucoma. The finding that the disc morphology is not significantly different between eyes with pigmentary glaucoma and eyes with primary open angle glaucoma despite significant differences in sex and refractive error agrees with previous studies in which the disc morphology was mostly independent of sex and refractive error in a range of -5 to +5 dioptres. ${ }^{8}$

There are factors limiting the present study. Owing to the deeper anterior chamber and similar keratometric readings, eyes with pigmentary glaucoma may have a longer axial length than eyes with primary open angle glaucoma with the same refractive error. A difference in axial length influences optic disc measurements since only anterior corneal curvature and refractive error are taken into account with the Littmann formula. According to Littmann, ${ }^{6}$ an increase in axial length by $2 \mathrm{~mm}$ from $24 \mathrm{~mm}$ to $26 \mathrm{~mm}$ increases the linear magnification factor in the Littmann formula by about $10 \%$. It means that the optic disc area measurements expressed in absolute size units (that is, millimetres) would haver to be multiplied by a factor of $(1.1)^{2}$, which is 1.21. It would lead to a significantly larger optic disc size in the pigmentary glaucoma group than in the primary open angle glaucoma group. Other measurements such as shape of the neuroretinal rim expressed as the ratios of the neuroretinal width measurements, cup/disc ratios, and the ratios of the alpha area to disc area and beta area to disc area are independent of fluctuations in the magnification factor. Against the fact that differences in axial length may have had a significant effect on the results of the present study was that there was no significant differ- ence in the mean perimetric defect and neuroretinal rim area measurements between the two groups. Furthermore, a difference in the depth of the anterior chamber of $20 \%$ (from $3.1 \mathrm{~mm}$ to $3.7 \mathrm{~mm}$ ) increases the magnification factor in the Littmann formula by only $0.6 \%$.

Interestingly, the mean maximal intraocular pressure values were significantly higher in the pigmentary glaucoma group than in the primary open angle glaucoma. This finding partially agrees with the results of a previous study performed in our department which found that eyes with high pressure juvenile onset primary open angle glaucoma had optic discs with specific characteristics including steep and deep cupping and only slightly enlarged areas of parapapillary atrophy. ${ }^{5}$ In agreement, a relatively small beta zone was found in both the present study and that relating to patients with high pressure juvenile onset primary open angle glaucoma. However, differences were found in the two studies with respect to the extent of parapapillary atrophy and cup depth between the two groups of patients. A reason for the discrepancy may be that in the eyes with juvenile onset primary open angle glaucoma, the maximal and minimal intraocular pressures were markedly elevated whereas in the present study in the eyes with pigmentary glaucoma, only the maximal intraocular pressure measurements were markedly increased. It is possible that high intraocular pressure peaks, with otherwise only slightly elevated intraocular pressure, do not lead to a pathognomonic morphology in the optic disc and retinal nerve fibre layer. In a parallel manner, eyes with pseudoexfoliative glaucoma compared with eyes with primary open angle glaucoma have significantly higher intraocular pressure peaks and a significantly larger pressure amplitude, while the mean minimal intraocular pressure measurements and the morphology of the optic disc and retinal nerve fibre layer do not show a clinically significant difference between the two glaucoma types. ${ }^{24}$

Supported by Deutsche Forschungsgemeinschaft (SFB 539).

Shields MB. Textbook of glaucoma. 3rd ed. Baltimore: Williams \& Wilkins, 1992:276-84.

2 Richardson TM. Pigmentary glaucoma. In: Ritch R, Shields MB, Krupin T, eds. The glaucomas. St Louis: Mosby, 1989: 981-95.

3 Weseley P, Liebmann J, Walsh JB, et al. Lattice degeneration of the retina and the pigment dispersion syndrome. $A m \mathcal{F}$ Ophthalmol 1992;114:539-43.

4 Jonas JB, Fernández MC, Naumann GOH. Glaucomatous parapapillary atrophy: occurrence and correlations. Arch parapapillary atrophy: occurrenc

5 Jonas JB, Gründler AE. Optic disc morphology in juvenile primary open-angle glaucoma. Graefes Arch Clin Exp Ophthalmol 1996;234:750-4.

6 Littmann H. Zur Bestimmung der wahren Größe eines Objektes auf dem Hintergrund des lebenden Auges. Klin Monatsbl Augenheilkd 1982;180:286-9.

7 Jonas JB, Schiro D. Localised wedge-shaped defects of the retinal nerve fibre layer in glaucoma. Br f Ophthalmol 1994 78:285-90.

8 Jonas JB, Gusek GC, Naumann GOH. Optic disc, cup and neuroretinal rim size, configuration, and 1988:29:1151-8. (Correction: Invest Ophthalmol Vis Sci 1988;29:1151-8. (Correction: Invest Ophthalmol Vis So

Spaeth GL, Hitchings RA, Sivalingam E. The optic disc in glaucoma: pathogenetic correlation of five patterns of cupping in chronic open-angle glaucoma. Trans Am Acad Ophthalmol Otolaryngol 1976;81:217-23. 
10 Hitchings RA, Spaeth GL. The optic disc in glaucoma. I: Classification. Brf Ophthalmol 1976;60:778-85.

11 Greve EL, Geijssen HC. The relationship between excavation and visual field in glaucoma patients with high and low intraocular pressures. In: Greve EL, Heijl A, eds. 5th Inter national Visual Field Symposium. The Hague: Dr W Junk, 1983:35-42.

12 Caprioli J, Spaeth GL. Comparison of the optic nerve head in high- and low-tension glaucoma. Arch Ophthalmol 1985; 103:1145-9.

13 Drance SM, Airaksinen PJ, Price M, et al. The correlation of functional and structural measurements in glaucoma patients and normal subjects. Am F Ophthalmol 1986;102: patients

14 Kitazawa Y, Shirato S, Yamamoto T. Optic disc hemorrhage in low tension glaucoma. Ophthalmology 1986;93:853-7.

15 Drance SM, Douglas GR, Airaksinen PJ, et al. Diffuse visual field loss in chronic open-angle and low-tension glaucoma. Am f Ophthalmol 1987;104:577-80.

16 Geijssen HC, Greve EL. The spectrum of primary open-angle glaucoma I: Senile sclerotic glaucoma versus high tension glaucoma. Ophthalmic Surg 1987;18: 207-13.

17 Geijssen HC, Greve EL. Focal ischaemic normal pressure glaucoma versus high pressure glaucoma. Doc Ophthalmol 1990;75:291-301.
18 Tuulonen A, Airaksinen PJ. Optic disc size in exfoliative, primary open angle, and low-tension glaucoma. Arch Ophthatmol 1992;110:211-3.

19 Caprioli J. Correlation between disc appearance and type of glaucoma. In: Varma R, Spaeth GL, eds. The optic nerve in glaucoma. Philadelphia: Lippincott, 1993:91-8.

20 Spaeth GL. A new classification of glaucoma including focal glaucoma. Surv Ophthalmol 1994;38:S9-17.

21 Jonas JB, Stürmer J, Papastathopoulos KI, et al. Optic disc size and optic nerve damage in normal-pressure glaucoma. Br f Ophthalmol 1995;79:1102-5.

22 Nicolela MT, Drance SM. Various glaucomatous optic nerve appearances: clinical correlations. Ophthalmology

23 Jonas JB, Gründler AE. Optic disc morphology in "age-related atrophic glaucoma". Graefes Arch Clin Exp Ophthalmil 1996;234:744-9.

24 Jonas JB, Papastathopoulos KI. Optic disk morphology in pseudoexfoliation syndrome. Am F Ophthalmol 1997;123: 174-80.

25 Jonas JB, Gründler AE. Optic disc morphology in juvenile primary open-angle glaucoma. Graefes Arch Clin Exp Ophthalmol 1996;234:750-4.

26 Jonas JB, Dichtl A. Optic disc morphology in myopic primary open-angle glaucoma. Graefes Arch Clin Exp Ophthalmol 1997;235:627-33. 